\title{
Research to improve the applicability of ICOLD Bulletin 164 on internal erosion
}

\author{
Rodney Bridle \\ Dam Safety Ltd, Great Missenden, United Kingdom
}

\begin{abstract}
ICOLD Bulletin 164 on internal erosion in existing dams, dikes and levees and their foundations is available in two volumes from www.icold-cigb.org. The Bulletin has been prepared because internal erosion results in many failures, causing numerous fatalities, but has not been well understood. The Bulletin has drawn on research and practice to develop an understanding of the mechanics of internal erosion. Using this new knowledge, the Bulletin makes it possible for engineers to estimate the water level at which internal erosion will lead to failure by each of the four initiating mechanisms: concentrated leak erosion, backward erosion, suffusion and contact erosion. Further research may provide knowledge to improve on engineers' ability to predict the response of dams to the hydraulic forces that initiate internal erosion. Examples from the Bulletin are used to show where more laboratory and field research may contribute to expanding the applicability of the new understanding of internal erosion mechanics, including methods to extend the range of soil gradings of vulnerable soils, to determine the extent of crest desiccation and cracking, and improved methods to determine in-situ permeability.
\end{abstract}

\section{INTRODUCTION}

Internal erosion causes about half of all dam failures, similar to the number caused by overtopping during extreme floods. Only about $6 \%$ of failures are caused by instability. Of the internal erosion failures, about one third occur in existing dams.

Situ Gintung is an example of an internal erosion failure of an existing dam. This $15 \mathrm{~m}$ high homogeneous embankment dam completed in 1930 near Jakarta in Indonesia, failed during a flood in 2009, causing between 100 and 200 fatalities (ICOLD, 2016). This tragic case and advancing knowledge led the ICOLD Embankment Dams Committee to decide to write guidance (a Bulletin) on internal erosion.

Internal erosion occurs when the hydraulic forces imposed by water flowing through the fill in embankments is sufficient to overcome the resistance of the materials in the dam and foundation. The greatest hydraulic forces normally occur when the water level in the reservoir is high during floods.

ICOLD Bulletin 164 (referred to in this paper as the Bulletin, Volume 1, Volume 2 and ICOLD 2015 and ICOLD 2016, respectively) gives new knowledge that makes it possible to estimate the hydraulic load - usually the water level - that will lead to initiation of internal erosion through the four initiating mechanisms:
1 Concentrated leak erosion, through cracks and openings in dams

2 Backward erosion, when the hydraulic gradients at the downstream toe of an embankment on sandy foundations are such that an erosion pipe initiates and erodes 'backwards' (upstream) eventually braking through into the reservoir

3 Suffusion, when the finer soils are driven through the pores in the matrix of coarse soils.

4 Contact erosion, which occurs at the interface between fine and coarse soils when the seepage forces from flow through the coarse soils are sufficient to erode the fine soil.

What follows is suggestions, from experience and from applying the knowledge in ICOLD Bulletin 164 (ICOLD 2015, 2016), for more research into various aspects of the four mechanisms to improve understanding of internal erosion and thereby assist engineers to more effectively investigate, analyze, strengthen (if necessary), and monitor dams to be capable of resisting internal erosion.

With apologies for any presumptuousness in appearing to instruct researchers, readers will see that most suggestions are for small advances from work already completed or in hand. Some hope that the approach similar to those adopted to develop the new understanding of internal erosion may be applicable to devising practical methods to resolve other long-term engineering enigmas. All want to extend 
the teamwork between researchers and practitioners to provide effective engineering solutions, based on engineering analysis, to protect dams against internal erosion and thereby limiting uncertainties about causing fatalities and damage, and the need for expenditure on excessive or unnecessary remediation.

\section{CONCENTRATED LEAK EROSION}

Most of the failures in existing dams result from concentrated leak erosion in cracks and openings.

Figure 1 shows situations where cracks may form in dams. Most result in cracking through the crest, and when water level rises, flow through the cracks may erode the soils in the walls of the cracks and lead to breach.

The Bulletin, in Chapter 3 of Volume 1, gives examples of formulae that can be used to find the shear stress imposed, and examples of the resistance to erosion provided by the hydraulic shear strength (called the 'critical shear stress') of a range of soils. If necessary, the critical shear stress can be measured in the Hole Erosion Test for plastic soils and the Jet Erosion Test in non-plastic soils. Chapter 4 in Volume 2 of the Bulletin gives details of these and other internal erosion tests.

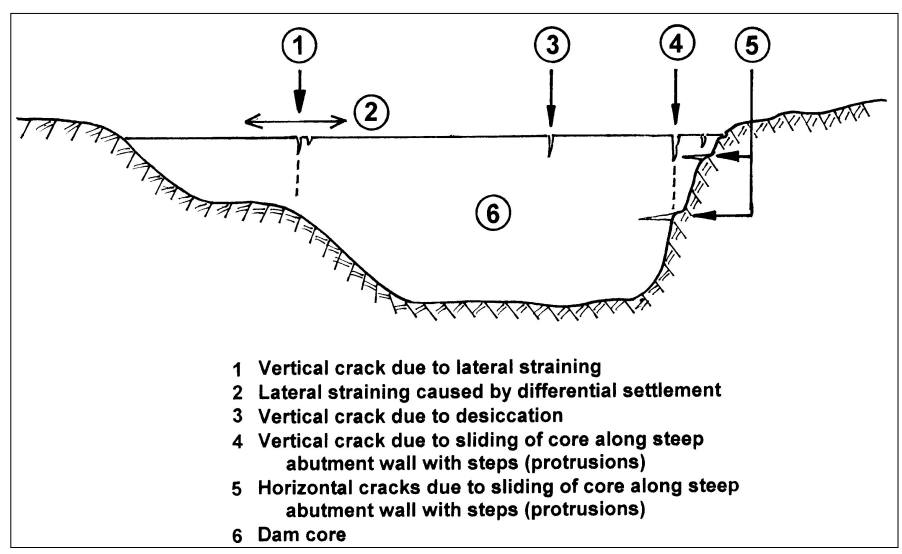

Figure 1. Showing situations where cracks may form in dams, note the vulnerability of the crest (from ICOLD 2015).

\subsection{Vertical cracks due to lateral straining}

Settlement after construction, seasonal swelling and shrinkage, water level fluctuations, earthquakes and long term creep may cause near vertical cracking in the crests of dams, particularly above unfavorable foundation profiles, as 1, 2 and 4 in Figure 1 illustrate.

Another vulnerable location is at the junction between the fill and the walls and floors of spillways passing through the crests of dams. The fill at high level is rarely wetted because extreme floods generating high water level rarely occur, consequently the fill at high level may dry and shrink away from the walls, creating a crack through which flood water may pass and cause erosion, leading to wash-out of the spillway.

Although cracks through the crest can be readily identified qualitatively, their exact locations, depths and widths cannot be reliably quantified. If it proved possible to determine the details, they would not be constant because as explained above the locations, widths and depths of cracks will change over time or suddenly, in the case of cracks opened during earthquakes.

At Situ Gintung, for example, the cracks had extended below the floor of the spillway during the long period when the reservoir was near-empty, and not closed during re-filling, resulting in the failure. The cracks were plainly not present previously as the embankment had held water and overflowed without mishap in the years between 1930 and 2009. No cracks or leaks had been seen during an engineer's inspection in 2008.

\subsection{Cracks limiting the filtering capability of fills}

In such uncertain circumstances, there is a constant possibility that 'dangerous' cracks will be formed at any time, through which water may flow and initiate erosion.

In 'zoned' dams, dams with more-or-less vertical zones, core, filters, transitions, shoulder fills, etc, non-plastic materials in the zones downstream of an eroding zone, the core, for example, may be capable of 'filtering' and thereby arrest and prevent the continuation of erosion.

In unzoned ('homogeneous') dams, there are no zones to provide filtering, and erosion, if initiated, can continue unchecked. Consequently unzoned ('homogeneous') dams are more vulnerable to internal erosion than zoned embankment dams.

However, the capacity of fills and filters to provide filtering can be limited if they contain fines $(<0.075 \mathrm{~mm})$. Table 1 , gives the likelihood that materials will 'hold a crack' and therefore be ineffective as filters.

Table 1. Likelihood for Filters with Excessive Fines Holding a Crack (Table 7.1, ICOLD 2015, from Fell et al 2008)

\begin{tabular}{|c|c|c|c|}
\hline \multirow{2}{*}{$\begin{array}{l}\text { Fines Plastici- } \\
\text { ty }\end{array}$} & \multirow{2}{*}{$\begin{array}{c}\text { Fines Content } \\
\% \text { Passing } \\
0.075 \mathrm{~mm}\end{array}$} & \multicolumn{2}{|c|}{$\begin{array}{l}\text { Probability of holding a } \\
\text { crack }\end{array}$} \\
\hline & & Compacted & Not compacted \\
\hline \multirow{5}{*}{$\begin{array}{l}\text { Non plastic } \\
\text { (and no ce- } \\
\text { menting pre- } \\
\text { sent) }\end{array}$} & $5 \%$ & 0.001 & 0.0002 \\
\hline & $7 \%$ & 0.005 & 0.001 \\
\hline & $12 \%$ & 0.05 & 0.01 \\
\hline & $15 \%$ & 0.1 & 0.02 \\
\hline & $>30 \%$ & 0.5 & 0.1 \\
\hline \multirow{4}{*}{$\begin{array}{l}\text { Plastic (or } \\
\text { fines suscep- } \\
\text { tible to ce- } \\
\text { menting) }\end{array}$} & $5 \%$ & 0.05 & 0.02 \\
\hline & $7 \%$ & 0.1 & 0.05 \\
\hline & $12 \%$ & 0.5 & 0.3 \\
\hline & $\geq 15 \%$ & 0.9 & 0.7 \\
\hline
\end{tabular}

Note: Fines susceptible to cementing in filters having a matrix predominately of sand sized particles (e.g. filters derived from crushed limestone). 
The background to Table 1 is discussed in Section 7.3 of Volume 1 of the Bulletin (ICOLD 2015). Plastic soils, as would be expected, were found to be more likely to 'hold cracks' than non-plastic soils.

In fact, the probability that plastic soils would hold a crack would be expected from conventional understanding of the behavior of plastic soils. Conversely, that non-plastic soils can hold cracks also defies conventional expectations of soil behavior. Cracks remaining open below water table or the phreatic surface would also be unexpected.

The explanations for these anomalies probably relate to soil moisture content and to the stress state imposed on the soils in tests and in the dams to which the case histories relate. Fills and filters above the phreatic surface are only partially saturated, pore pressures are negative (in suction), and often subject to stresses that cause 'arching', the ability of soils to form an arch leaving soils below in a state of low confining stress, even if no opening is formed below the 'arch'. Openings are created by hydraulic fracture when pore pressure exceeds the minimum principal total stress.

In these circumstances, pore water suction and imposed stresses hold cracks in the crest open. This situation may fluctuate and vary over time, as mentioned above, but markedly changed circumstances, a sudden very high water level, or an earthquake, may allow leakage through the crack, causing erosion or supplying water to saturate the soil, breaking the pore water suction and causing collapse of the crack and arresting any erosion.

\subsection{Rapidity of closure of cracks after water enters}

The critical factor in these circumstances is the rapidity of closure of the crack or opening after water enters it. Will it collapse rapidly before any damaging erosion occurs, or will it collapse slowly enough for the water flowing through the collapsing crack to transport the collapsed material downstream, thereby enlarging the crack sufficiently to allow substantial flow through the crest to cause breach.

Bonelli \& Brivois (2008) and work by Foster summarized in Figure 8.1 in Volume 1 of the Bulletin demonstrate that openings can grow at a rapid rate, but on the assumption that the openings will remain open and do not collapse as they enlarge.

Further work on this aspect, and on the development of methods to assess the hydraulics of flow into cracks allowing for infiltration into the surrounding fill, thereby reducing the erosive force applied by the flow of water along the crack, would assist engineers to assess the situation more realistically.

\subsubsection{Sand castle tests}

Currently, the issue of crack-closing in potential filters is examined by empirical tests, some based on the 'sand-castle' test put forward by Vaughan \& Soares (1982), to confirm that potential filters were not 'cohesive' (in the terminology of the time, now called 'non-plastic'). The 'sand-castle' is that built by (British) children using their 'buckets and spades' on beach holidays, to fill a mould (the 'bucket') with moist beach sand, tap on the sand exposed at the open top of the mould with the 'spade' to compact it, invert the mould and stand it on the beach, then carefully lift the mould off the sand to reveal the 'castle', a mould shaped sand structure.

The 'test' is to make a castle of potential filter material on a tray, and slowly pour water into the tray to a depth of about $50 \mathrm{~mm}$. If the 'sand' is not 'cohesive' the submerged lower portion of the castle slumps, removing support for the upper parts of the castle which tumble down into the water and slump.

An example of a sand castle test is shown on Figures 2, 3, 4 and 5. The sample tested was from glacial till shoulder fill, shown on Figure 6, of the 'typical' British dam' described by Bridle (2008). Its grading is shown on Figure 7, which also shows the no-, some- and excessive-erosion limits determined using the filter erosion boundaries concept (Foster \& Fell, 2001). More details are given in ICOLD (2016).

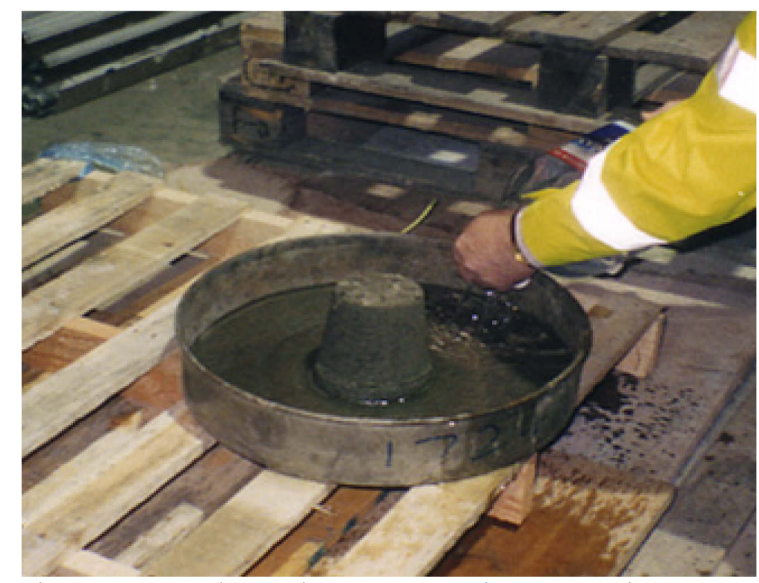

Figure 2. Sand Castle Test: Pouring water into tray containing glacial till sand castle

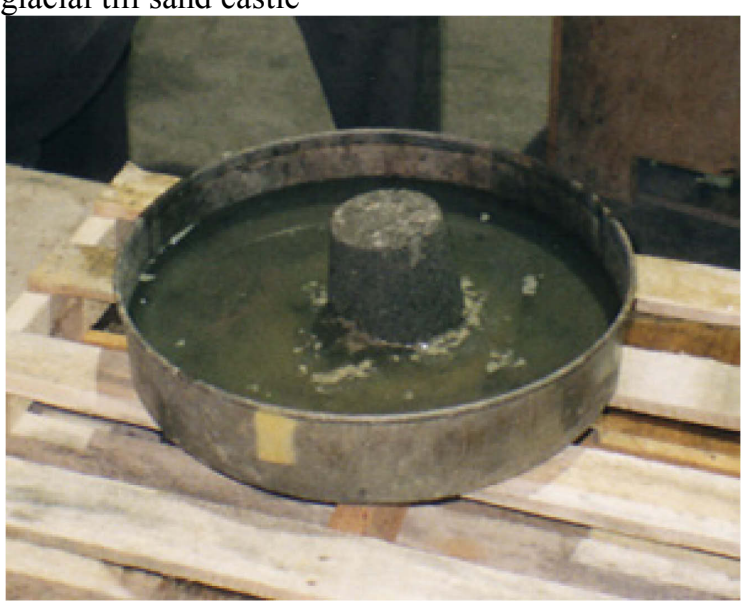

Figure 3. Sand Castle Test: glacial till sand castle beginning to slump (look under surface of water). 


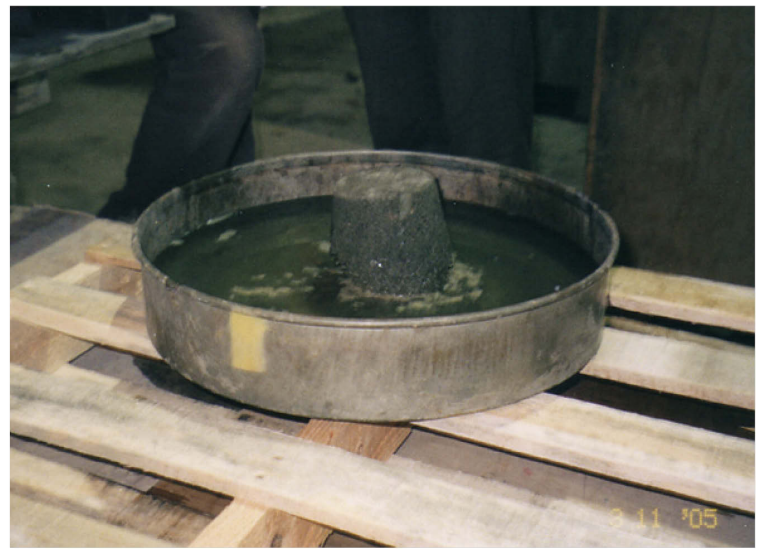

Figure 4. Sand Castle Test: glacial till continues to slump

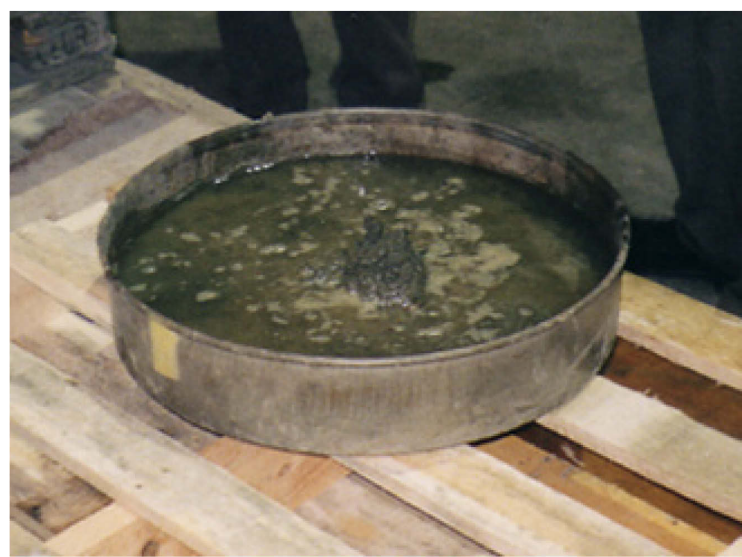

Figure 5. Sand Castle Test. Glacial till castle has collapsed, demonstrating that the till is not cohesive.

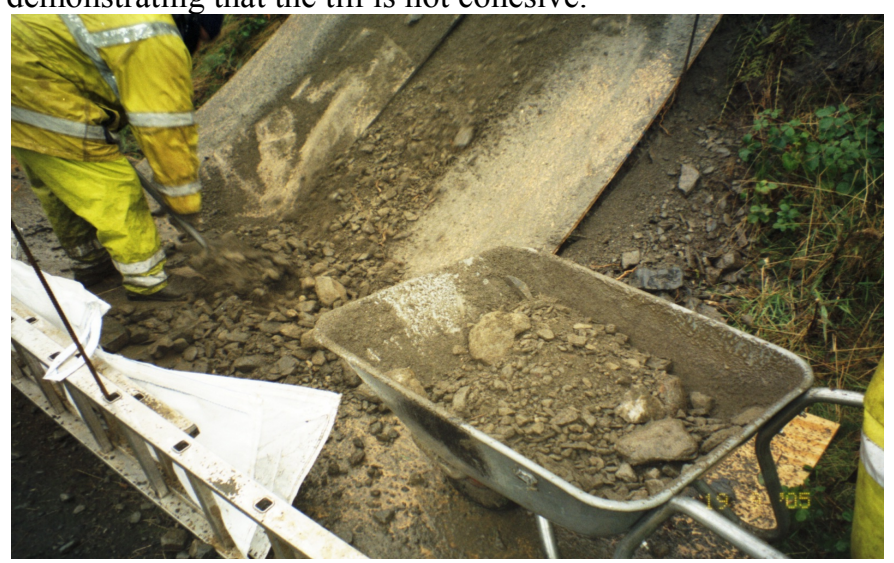

Figure 6. Taking a sample of glacial till used as shoulder fill in the typical 1904 British dam (from Bridle, 2008).

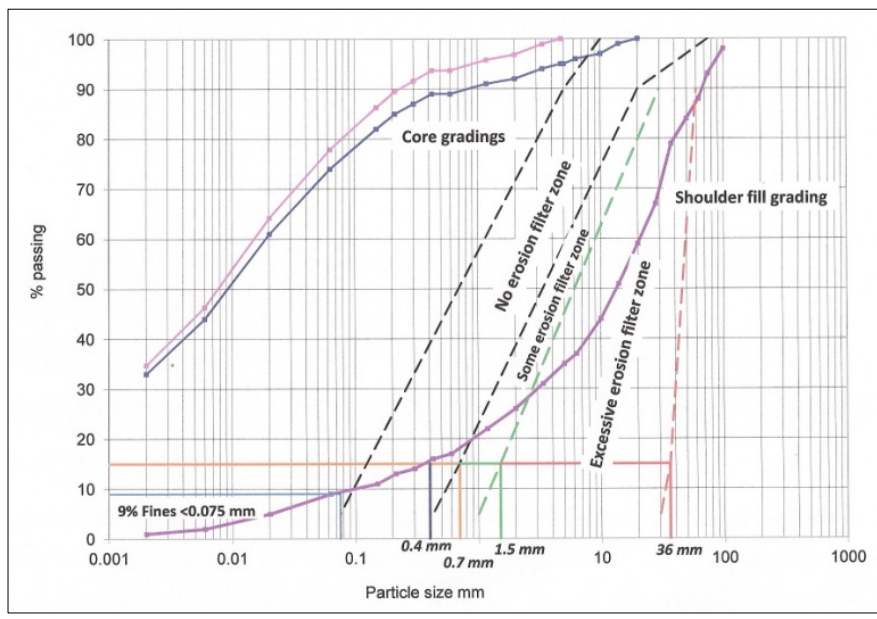

Figure 7. Showing core grading, no-, some- and excessiveerosion filter boundaries and glacial till shoulder fill grading including $9 \%$ fines $(<0.075 \mathrm{~mm})$.
The fines content of the till was $9 \%$. Table 1 shows that there is a likelihood of about $0.1 \%$ to $1 \%$, that it would hold a crack. The collapse of the sand castle, shown in Figure 5, shows that the till is nonplastic.

The time to collapse of the sand castle was not taken, but it was brief, two to three minutes. The permeability of the sample, when saturated, was measured in the Transport Research Laboratory large permeameter $0.3 \mathrm{~m}$ square, one meter long, large permeameter. The permeability ranged from $1.0 \mathrm{E}-06 \mathrm{~m} / \mathrm{s}$ to $6.1 \mathrm{E}-05 \mathrm{~m} / \mathrm{s}$, for dry densities of $2.06 \mathrm{Mg} / \mathrm{m}^{3}$ and $2.19 \mathrm{Mg} / \mathrm{m}^{3}$ respectively.

\subsubsection{Pore water suction, saturation and collapse in sand castle tests}

As Vaughan \& Soares (1982) explain, the apparently simple sand castle test is a 'shear test under low vertical load, a compression test at zero effective confining pressure and small shear stress, a sensitive detector of a small degree of cohesion'.

When the mould is removed, the castle slumps slightly, putting the pore water (and air) into suction. When the base of the castle is wetted water is drawn into the pores which fill with water, the pore water pressure in the now saturated sand becomes positive and the sand gradually slumps to its angle of repose, removing support from under the only partly saturated sand above which tumble down.

The collapse of the castle usually occurs over about two minutes, a finite time, and this raises doubts about the effectiveness of the filter in the dam. Will it hold a crack for long enough to allow erosion to develop towards breach?

Soroush et al (2012) developed a variation of the sand castle test to examine the rate of crack closure. Many details have been included to enable comparisons between samples, and the time to collapse is measured. However, in this test, the water level has to be held just at the level of the base of the 'castle'. This means that water is drawn up into the sample by capillary action only, and the sand at the base of the castle can never become saturated. Consequently the pore pressure remains (slightly) negative and prevents collapse.

\subsubsection{Crack box tests}

Howard et al (2015) report on testing filters for crack holding properties using a large scale hinged test box. It has an upstream reservoir and downstream channel to collect water and eroded materials. Drains were provided on the floor to allow free downward drainage simulating the situation in vertical filter wall 'chimney' drains.

Single filters, two-stage (fine and coarse) filters and core and filters have been tested, placed at various moisture contents and compacted to various densities. Filter widths were up to $1.5 \mathrm{~m}$ (5-feet) for 
single filters and $0.6-0.9 \mathrm{~m}(2-3$-feet $)$ for two stage filters.

Cracks, about $25 \mathrm{~mm}$ wide at the crest, were opened by lifting the box at the hinge to create a vertical upstream-downstream crack through the filter (and core in some tests) in the crest of a dam as might occur in an earthquake, or from differential and seasonal settlement as described earlier. The reservoir was then opened allowing water to flow into the cracks and observations of closure, sloughing and erosion to be made. The duration of the tests was not recorded.

The results, in summary, were that cracks in denser heavily compacted soils remained open, wider filters closed more readily than narrow filters, and two-stage filters were more effective than single filters.

The results reflect some features of the test. When the crack is formed, the pore pressure in the adjoining soil will go into suction. Also, the compaction of the filters will impose high horizontal stress in the upstream downstream direction and sustain 'arching'. The two factors will resist the ability of the filters to collapse promptly on saturation. They will be more marked in the heavily compacted soils than the less dense ones.

When cracks did not close, the reservoir was not able to supply sufficient water and the water level dropped, consequently little of the surface area of the crack in the filter was in contact with water, and only a small part of it could have drawn in water to make the filter swell, saturate and collapse.

Wider filters provide a greater area in contact with water, allowing swelling and saturation to progress more rapidly.

The two stage filters were more effective because the coarse filter trapped particles eroded from the fine filter and progressively blocked the base of the crack.

Further tests at constant upstream and downstream water level would provide information on time to closure. Such tests would simulate the situation in earthquakes where the shaking may open cracks to below reservoir water level. Tests to examine whether cracks, initially open down to water level, close as water level rises would simulate the situation during floods. Tests with varying upstream and downstream water level could be devised to examine the influence and importance of the width of filters. Consideration of the possibility of using the test results to provide data for numerical analysis and modeling would make the results widely applicable.

\subsubsection{Pull-out and trenching tests}

Mejia (2013) developed pull-out tests and trenching tests to check whether transition and filters proposed for the earthquake protection berm at Matahina Dam would not hold cracks. The materials were placed around horizontal $150 \mathrm{~mm}$ and $200 \mathrm{~mm}$ dia steel pipes in a test embankment. The coarser Transition material $\left(\mathrm{d}_{50} \approx 12 \mathrm{~mm}\right)$ collapsed as the pipes were carefully withdrawn. When the pipes were withdrawn from the finer Filter $\left(\mathrm{d}_{50} \approx 1.2 \mathrm{~mm}\right)$ longitudinal cavities remained but collapsed immediately when flooded. However, a cavity similar to the initial one had formed at a higher level. In the trench tests, it proved impossible to excavate a trench in the Transition material as the sides fell in during excavation. Trenches in the Filter stood vertically to the full depth of the test embankment (about $1.5 \mathrm{~m}$ ) and collapsed when the trench was filled with water, with small wedges of material sloughing from the sides at increasing intervals.

\subsubsection{Analysis to assess rapidity of crack closure}

The examples above confirm that a delay would be expected as water was drawn into the fill leading to positive pore pressures and collapse to close the walls of cracks. Wetting up partially saturated soils in filters and fills plainly takes a short but finite time. Analyses of the consolidation (swelling) process taking place during sand castle, crack box and other tests could provide helpful data on permeability and rate of swelling of non-plastic soils during the process of proceeding from partial to complete saturation, leading to collapse of cracks and openings.

These parameters may be applied to examine the vulnerability of crests to erosion through cracks. This may or may not provide the means of determining whether or not crests should be protected against internal erosion, decisions that currently, in the $a b-$ sence of the means of analysis, are taken as precautions in accordance with good practice.

\subsection{Desiccation}

Prior to the failure of Situ Gintung dam, mentioned earlier, the reservoir had been almost empty, and the breach occurred as it refilled rapidly during a heavy rainstorm. The breach was at the spillway location, and is thought to have resulted from concentrated leak erosion when water entered desiccation cracks in the fill below the spillway channel floor, causing uplift and rupturing the floor, allowing water to escape and flow rapidly over the fill, eroding it and deepening the breach.

Desiccation is one of the mechanisms that form cracks and openings in the crest of dams, as indicated by Item 3 in Figure 1. The desiccation process forms hexagonal shrinkage cracks, often seen in sediment on the bed of reservoirs emptied by drought. The drying and shrinking process seems to bear similarities to the cooling process that forms hexagonal columns in basalt, as can be seen at the Giant's Causeway in Co Antrim, Northern Ireland.

The vertical hexagonal columns in both soil and basalt are cut at intervals by horizontal joints. Con- 
sequently, the columns topple readily when subjected to lateral forces and uplift on the horizontal joints, as occurs when water levels rise rapidly.

To avoid such situations, the Bulletin recommends that a watertight barrier be extended down into the crest (below the spillway floor in the case of Situ Gintung) to below the depth that desiccation is expected to penetrate. What that depth is cannot be easily predicted.

Dyer et al (2007) and CIRIA et al (2013) investigate some of these matters, but further research work to develop a better understanding of the physical processes in desiccation may lead to more certainty in engineering solutions to address it, for example:

1 Which soils are susceptible to desiccation cracking? Is it only plastic soils (clays) or are nonplastic soils, particularly those with fines, also susceptible.

2 To what depth do desiccation cracks descend, and do they penetrate below the phreatic surface in fills?

3 How rapidly do they penetrate downwards, as seems to have occurred at Situ Gintung?

4 How rapidly do they close as water level rises, plainly not as rapidly as water level rose at Situ Gintung?

5 When desiccation cracks 'close' as the fill wets up after drying out, do relict hexagonal columns and horizontal joints remain, making the dam crests in susceptible soils permanently vulnerable to damage?

\section{BACKWARD EROSION PIPING}

\subsection{Limitations of present knowledge}

The Bulletin reports several approaches to analysis of the potential for backward erosion piping to occur. The Sellmeijer approach provides a direct route, relating the hydraulic gradient that will lead to failure by backward erosion to soil properties, soil erodibility and geometry in the following relationship:

$\mathrm{H} / \mathrm{L}=\mathrm{F}_{\mathrm{R}} \mathrm{F}_{\mathrm{S}} \mathrm{F}_{\mathrm{G}}$

The details of the F factors are given Volume 1 of the Bulletin (ICOLD 2015) and examples of applying them are given in Volume 2 (ICOLD 2016). $\mathrm{H} / \mathrm{L}$, the critical gradient at which backward erosion will lead to failure, is as defined by Figure 8 .



Figure 8. Defining parameters used in backward erosion

The 'gradient' is simply measured, being water depth over bottom width of the embankment, although it is local gradients at the downstream toe that initiate the erosion and formation of an erosion pipe working upstream towards the reservoir.

Backward erosion is very actively researched. Van Beek et al (2014) and Allan et al (2015) examine the detailed mechanics. However, there are practical limitations to the application of the Bulletin, including the narrow range of grading to which Sellmeijer and Allan et al (2015) apply, the uncertainty of initiation of backward erosion pipes from below 'confining layers' and identifying where backward erosion may occur in long structures such a flood embankments passing over varying underlying materials.

\subsection{Limited range of gradings}

The Sellmeijer approach, largely based on the results of the IJkdijk trial embankment, strictly applies to uniform fine to medium sand $(\mathrm{U}=1.3-2.6), \mathrm{d}_{70}$ size $0.15 \mathrm{~mm}$ to $0.43 \mathrm{~mm}$ (see Table 4.1 in ICOLD 2015). Interestingly, such soils do occur naturally at AV Watkins dam (see ICOLD 2016), but most do not, as the glacial till shown on Figure 7 demonstrates.

\subsection{Backward erosion potential of crevasse splay gravels}

Robbins et al (2015) report work in progress in the USACE laboratory examining backward erosion in coarse sands and fine gravels. The materials were selected as being representative of those found in crevasse splays, where gravels have broken through natural levees at times of spate and flood embankments have subsequently been constructed over them. This is an example of using knowledge of river and floodplain morphology, illustrated in Figure 9 , to assist in predicting the foundation materials that might be encountered below dams, dikes and levees. 


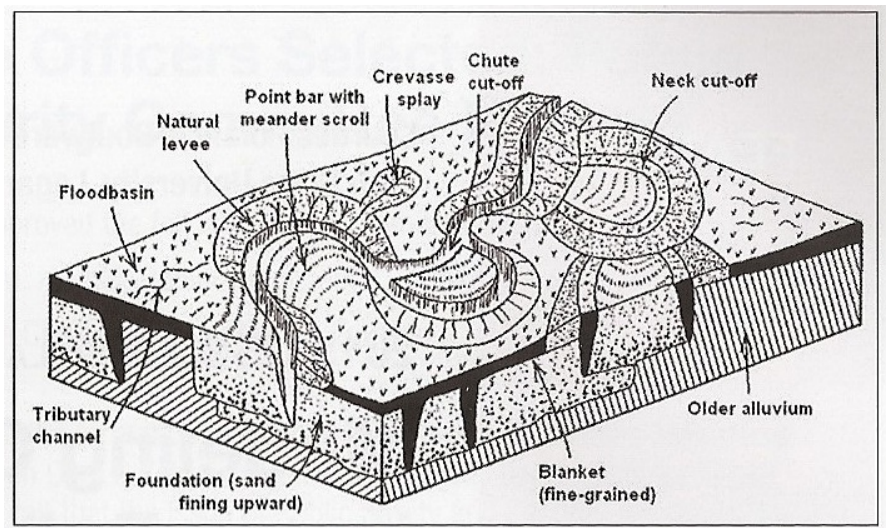

Figure 9. Geomorphic features within a meandering river environment (from Polanco-Boulware 2015)

\subsection{Initiation of backward erosion from under confining layers}

Vandenboer et al (2014) examined how the progress of the erosion pipe is fuelled by the groundwater in the surrounding aquifer, of depth D in Figure 8. Sufficient water must be available to fuel the erosion at the head of the pipe as it works towards the reservoir, and to remove the eroded sand particles along the pipe towards the toe of the embankment.

In the circumstances shown in Figure 8, known as the $2 \mathrm{D}$ situation, where the erosion initiates from a continuously exposed sand layer (in a ditch in the figure), the 'width' and volume of the aquifer supplying the many potential backward erosion pipes initiating in the ditch is limited, consequently the critical head in these circumstances is high.

In circumstances where the sand layer is below a 'confining layer' of clay or fine soil, known as the 3D situation, the backward erosion initiates through a hole, developed by uplift from high local upward water pressure at points where the confining layer is locally thin or cracked. The volume of the aquifer supplying the pipe in these circumstances is large, and backward erosion pipes leading to failure will develop at lower heads than in the 2D situation.

Consequently, the onset and possible failure by backward erosion of embankments with the sand layer covered by a downstream confining layer, which may occur at low head, is not predictable. This could be avoided if filtered outlet pipes were installed at designed spacings to release water from the aquifer to prevent unexpected break-throughs initiating backward erosion to failure.

\section{CONTACT EROSION}

There seems little experience of contact erosion, other than in embankments on the Rhine and the Rhone. However, contact erosion may be important in unzoned ('homogeneous') dams and embankments. Such embankments do not have vertical zones which may provide filtering. The fill is often heterogeneous, mixed, but commonly includes horizontal layers, which may be of sharply contrasting grading and permeability. High water level during floods may generate a sufficiently high velocity in the coarse layer to initiate erosion of the fine layer.

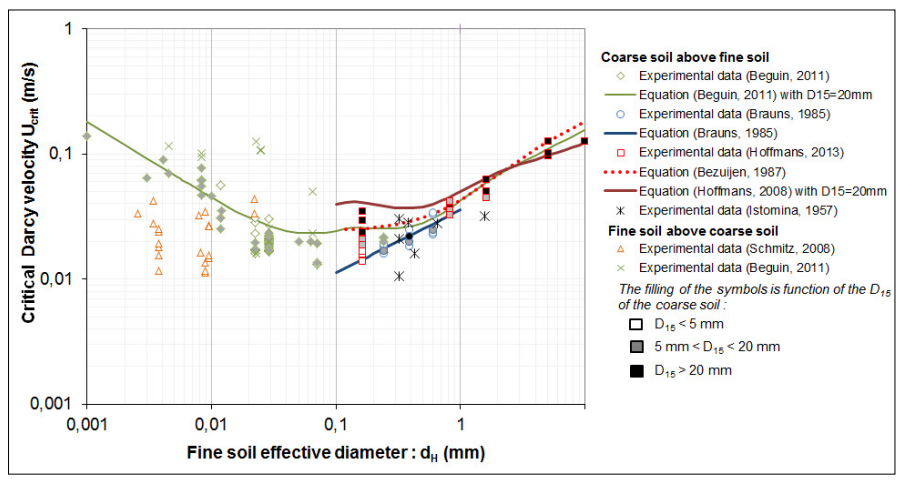

Figure 10. Critical Darcy velocities for initiation of contact erosion of silt and sand above and below gravel (Figure 5.2 in ICOLD 2015, courtesy of Dr Remi Beguin)

As Figure 10 shows, the onset of contact erosion in different fine soils can be determined from the Darcy velocity in the coarse soil.

Darcy velocity, $\mathrm{V}=\mathrm{k} . i$, where $\mathrm{k}$ is permeability and $i$ the hydraulic gradient. The gradient can be determined from piezometer records, and increased to determine the Darcy velocity at higher water levels. ICOLD (2016) in Chapter 3 discusses leakage detection and the determination of in-situ permeability. Where leakage quantity, hydraulic gradient and the area of discharge can be determined, overall in-situ permeability can be estimated. Commonly in existing dams these factors are not known, leakage may not be visible, for example. Investigations can determine in-situ permeability as boreholes are advanced, from piezometers and assessed using Permeafor and CPT-Hydraulic Profiling Tools (ICOLD 2016), but these provide isolated measurements of what is a markedly variable parameter.

\subsection{Determining in-situ permeability from temperature monitoring}

Geophysical leakage detection methods using soil temperature measurements provide more widespread information. Figure 11 shows the records from a temperature probe investigation, a contour map of temperatures in the embankment. A number of profiles give similar 'contour maps' across the embankment from upstream to downstream.

The results of such investigations are currently read directly to identify preferred seepage routes. They can also be used to determine pore velocity, but not Darcy velocity (Dornstadter \& Heinemann 2012). 


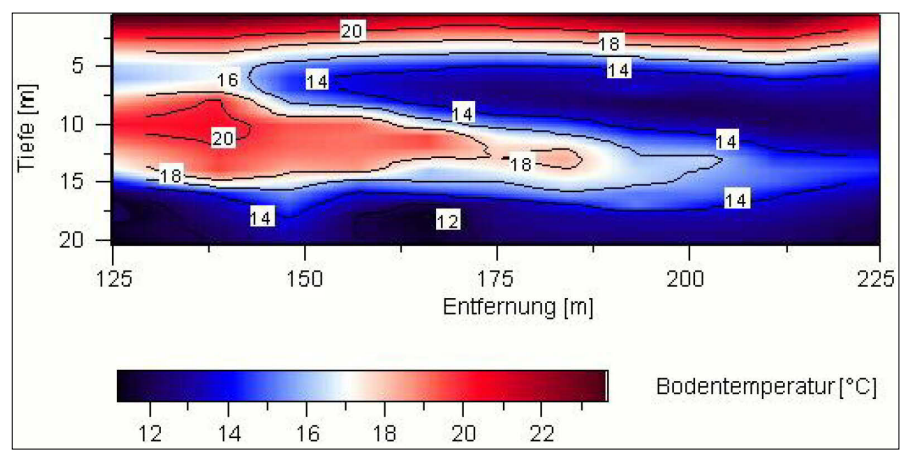

Figure 11. Temperature distribution recorded from an array of temperature probes (Figure 3.2 in ICOLD 2016, courtesy of GTC Kappelmeyer)

They do not, however, provide in-situ permeability values, and therefore cannot be applied using the methods in the Bulletin to identify zones where contact erosion could initiate, for example. If further research and consideration of the physical processes made it possible to 'invert' the temperature contours into permeability contours, the temperature probe investigations, and possibly other geophysical methods too, would provide data in the form needed to apply the Bulletin to examine the vulnerability of embankments to internal erosion. This approach would then ensure that deficient embankments were remediated and avoid wasted remediation which may occur if innocuous 'preferred seepage routes' are taken to be damaging.

\section{SUFFUSION}

Seminal work by Skempton \& Brogan (1994), demonstrated that suffusion - the erosion of suffusive fines through the pore spaces in the matrix of coarser grains, which carry the bulk of the load in suffusive soils - occurs under low applied hydraulic gradients, less than the gradients of about one that cause uplift.

To address the vulnerability of embankments to suffusion, it is necessary to determine from the soil properties, usually geometric properties, grading, if the soil is potentially suffusive, and if it is suffusive, the hydraulic load, usually hydraulic gradient, at which suffusion will initiate. Currently this entails separate investigations, first to collect entire samples, usually from saturated soils below water table, and determine the gradings and susceptibility to suffusion, and then to determine the hydraulic gradient at which suffusion will occur.

Developing from Skempton \& Brogan (1994), Li $\&$ Fannin (2008) proposed a hydro-mechanical criterion deduced from tests on suffusive materials, which potentially provides the critical hydraulic gradient from soil properties alone. Starting from the fact that seepage failure occurs in stable soils under the Terzaghi critical hydraulic gradient, $i_{\mathrm{CT}}$, Fannin and $\mathrm{Li}$ deduced the critical gradient, $i_{\mathrm{C}}$, for any un- stable soil, from the proportion of the effective stress $\alpha$ sustained by the fines:

$i_{C}=\alpha \cdot i_{C T}=\alpha \frac{\gamma^{\prime}}{\gamma_{W}}$

where $\gamma_{\mathrm{w}}$ and $\gamma^{\prime}$ are the water and buoyant soil specific weight and $\alpha$ is the reduction factor of the vertical effective stress $\sigma_{\mathrm{V}}^{\prime}$ carried by the finer particles in the internally unstable soil as was first proposed by Skempton \& Brogan (1994). The finer grains carry a reduced portion of the effective stress, $\sigma_{f}^{\prime}$ :

$\sigma_{f}^{\prime}=\alpha \cdot \sigma_{V}^{\prime}$

The reduction stress factor $\alpha$ is related to the mobility of the finer particles and is dependent on the Kovacs (1981) geometric criterion $\mathrm{d}^{\prime}{ }_{85} / \mathrm{O}_{50}$, where $\mathrm{d}_{85}$ is the $\mathrm{d}_{85}$ of the finer fraction of soil and $\mathrm{O}_{50}$ is the effective constriction size of the coarse fraction, as follows ( $\mathrm{Li}, 2008)$ :

$\alpha=3.85\left(\mathrm{~d}_{85} / \mathrm{O}_{50}\right)-0.616$

The relationship provides $\alpha$, which can be applied in the expression above to give the gradient at which the soil will erode by suffusion.

\subsection{The challenge of determining $O_{50}$ and the gradient at which suffusion initiates}

The challenge is in determining $\mathrm{O}_{50}$, which is related to constriction size distribution, the inverse of particle size distribution.

$\mathrm{Li}$ (2008) gives an expression from Kovacs (1981) for estimating $\mathrm{O}_{50}$, but it is complex. Several workers, notably Witt and Vincens examine constriction sizes (e.g. Witt \& Vincens, 2012). Taylor et al (2015) used micro-CT (X-ray micro-computed tomography) scans to determine constriction sizes. Taylor et al (2015) scanned real soil - irregular sand grains - and found that the constriction sizes at the coarse end of the constriction size grading were smaller than those previously estimated by other means. This limits the size of pore spaces available for suffused fines to pass through, possibly explaining why some soils identified by current methods as suffusive do not suffuse.

These sophisticated methods do not yet offer a means of readily determining $\mathrm{O}_{50}$ which could be used by practitioners, but research into simpler methods or techniques to capture the data needed would be very useful, as it would make it possible to estimate the gradient at which suffusion would occur directly from soil properties.

\subsection{Suffusion, boiling or heave and uplift}

When soils are found to be non-suffusive (called 'stable' by Kenney and Lau, 1985, 1986), they may 
be vulnerable to boiling or heave (called 'hydraulic heave' by Aulbach \& Ziegler 2015).

Figure 12 summarizes the results of the Skempton \& Brogan (1994) tests. Samples A and B were suffusive, samples $\mathrm{C}$ and $\mathrm{D}$ were not. In $\mathrm{A}$ and $\mathrm{B}$, the suffusive samples, when suffusion occurred, there was strong and even violent piping of fines, while the gravel particles remained stable.



Figure 12 Grain size distribution curves of soils in Skempton \& Brogan (1994) tests. Samples A and B were suffusive, C and D were not. Suffusion in upward flow initiated at critical hydraulic gradient $i_{c r}=0.2$ in $\mathrm{A}$ and $i_{c r}=0.34$ in $\mathrm{B}$. In non-suffusive samples $C$ and D, 'general piping' occurred at $i_{c r}=\gamma^{\prime} / \gamma_{\mathrm{w}} \approx 1.0$.

In $\mathrm{C}$ and $\mathrm{D}$, the non-suffusive samples, there was strong general piping when the hydraulic gradient was at the theoretical limit for non-suffusive (stable) soils, 1.03 in this case, when the effective stress was zero $(\sigma-u=0)$ on all the particles, coarse and fine. This is a quicksand condition, plainly undesirable at the downstream toe of an embankment, for example.

It is not possible to determine with confidence the hydraulic gradients close to the toe of embankments on sandy foundations. The 'gradient' used to investigate vulnerability to backward erosion is not the gradient close to the toe, which actually initiates formation of the backward erosion pipe, but the simple one shown on Figure 8 of water depth/length of base of the embankment, determined by tests, models and large scale trials.

Aulbach \& Ziegler (2015) address the issue for sheet-piled boxes by models applying many geometric and soil parameters.

Uplift, the situation when there is a confining layer at the toe, as discussed in Section 3 on backward erosion above, presents similar challenges, particularly in assessing whether the uplift, pore pressure, is sufficient to raise the confining layer locally, causing blow-outs. In some circumstances, puncturing the confining layer with filtered vertical drains reduces pore pressure sufficiently to prevent rupture.

If researchers could address and develop methods that provided definite results, much uncertainty and unnecessary expenditure on cut-off barriers or excessive width of embankments, for example, could be avoided.

\section{CONCLUSIONS AND RECOMMENDATIONS}

The knowledge included in ICOLD Bulletin 164 on internal erosion in existing dams, dikes and levees, is the product of the dedicated work of researchers and practicing engineers over recent years. The purpose of the Bulletin is to disseminate this knowledge to practitioners to assist them in making dams and levees more effective and safer.

The fundamental point about internal erosion is that it occurs when the hydraulic forces exceed the ability of the soil to resist those forces. Without water internal erosion cannot occur. The soil's resistance is a combination of its inherent soil properties and the state of stress in which it exists in the embankment. The various ways in which the three factors combine to produce various outcomes is elegantly summarized in the Garner \& Fannin (2010) internal erosion Venn diagram, but without the hydraulic forces imposed by water internal erosion cannot occur.

The paper makes suggestions for further research to improve the applicability of the new knowledge. Prior to recent work, an important, often the only, method available to engineers to design hydraulic structures on sandy foundations was that of Bligh (1910) improved by Lane (1935). The Bulletin demonstrates how concentrated research has led to a substantial progress in understanding internal erosion mechanics and how to investigate, analyze and design for it.

The suggestions here are to encourage further research to better understand some of the processes, and to apply well tried techniques, particularly numerical analysis, to produce more definite results, and thereby reduce uncertainty which may lead either to failures, loss of life and damage to property, or to wasted expenditure on unnecessary precautionary remediation justified only by 'good practice'.

The topics suggested are:

1 Cracks, rate of closing of cracks in non-plastic soils in dam crests, including further testing and analysis of the swelling process that breaks pore suction and leads to saturation and collapse, and of the hydraulics related to the balance of flow through, and infiltration, from cracks

2 Desiccation, physics of desiccation, depth of penetration, rate of penetration, relict cracks

3 Hydrogeology and design parameters of filtered boreholes to control onset of backward erosion under downstream confining layers

4 Modifying inversion of temperature and other data from geophysics investigations to produce soil parameters for direct application in methods of analysis in the Bulletin

5 Develop simple means of determining $\mathrm{O}_{50}$, effective constriction size of the coarse fraction, to facilitate estimation of critical gradient in suffusion from soil gradings 
6 Develop methods to estimate hydraulic gradients causing heave (or boiling) and uplift in nonsuffusive soils at the downstream toe of embankments

\section{ACKNOWLEDGEMENTS}

The assistance and enthusiasm of several young researchers, whose findings are seminal to the Bulletin, and the work of Dr Jean-Jacques Fry and Professor Robin Fell, who have played a major part in advancing understanding of internal erosion and wrote most of Volume 1, is much appreciated. The contributions to knowledge and the support of the ICOLD European Working Group on Internal Erosion, the ICOLD Technical Committee on Embankment Dams, and many agencies and dam owners are also acknowledged with thanks.

\section{REFERENCES}

Allan, R. Peirson, W. \& Douglas, K. 2015. Laboratory experiments and numerical modeling of backward erosion piping. Proceedings, XVI Dam Monitoring International Conference, TKZ2015, Wierchomla, Poland, 141-151.

Aulbach, B. \& Ziegler, M. (2015). Design formula for the safety against hydraulic heave. Proceedings of the XVI ECSMGE Edinburgh doi:10.1680/ecsmge.6067-8, 907-912

Bligh, W. G. 1910. Practical design of irrigation works, Second edition, Constable, Edinburgh.

Bonelli, S. \& Brivois. O. 2008. The scaling law in the hole erosion test with a constant pressure drop. Int. J. Numerical Methods in Engineering, 1573-1595.

Bridle, R. 2008. Assessing the vulnerability of a typical British embankment dam to internal erosion. $15^{\text {th }}$ Conference British Dam Society, University of Warwick, Thomas Telford London 13-28.

CIRIA, French Ministry of Ecology, \& USACE 2013. The International Levee Handbook, C731, CIRIA, London (ISBN: 978-0-86017-734-0). Go to: www.ciria.org

Dornstadter, J. \& Heinemann, B. 2012. Temperature as tracer for in-situ detection of internal erosion. Proc ICSE-6 $\left(6^{\text {th }}\right.$ International Conference on Scour and Erosion) Paris, August 27-31, Société Hydrotechnique de France, Paris, Paper 214, 1369-1375.

Dyer, Mark, Utili, Stefano, and Zielinski, Marcin 2007. The influence of desiccation fine fissuring on the stability of flood embankments. FRMRC Research Report UR11 (available from: www.floodrisk.org.uk)

Foster, M. \& Fell, R. 2001. Assessing embankment dams filters which do not satisfy design criteria. J. Geotechnical and Geoenvironmental Engineering, ASCE, Vol.127, No.4, May 2001, 398-407.

Garner, S.J. \& Fannin, R.J. 2010. Understanding internal erosion: a decade of research following a sinkhole event. International Journal on Hydropower and Dams, 17(3), 9398.

Howard, T. Rudkin, C. \& Irey, P. 2015. Large-scale filter performance tests. Association of State Dam Safety Officials Conference 2015.

ICOLD 2016. Internal erosion of existing dams, levees and dikes, and their foundations. Volume 2: Investigations, testing, monitoring and detection, remediation and case histo- ries. Internal erosion processes and engineering assessment. International Commission on Large Dams, Paris. Preprint 5 February 2016 from: http://www.icold-cigb.org.

ICOLD 2015. Internal erosion of existing dams, levees and dikes, and their foundations. Volume 1: Internal erosion processes and engineering assessment. International Commission on Large Dams, Paris. Preprint 19 February 2015 from: http://www.icold-cigb.org.

Kenney, T.C. \& Lau, D. 1985. Internal stability of granular filters. Canadian Geotech. J., Vol. 22, 215-225.

Kenney, T.C. \& Lau, D. 1986. Closure to: internal stability of granular filters. Canadian Geotech. J., Vol. 23, 420-423.

Lane, E. W. 1935. Security from under-seepage masonry dams on earth foundations. Proc. ASCE [republished with discussions in 1935 in Transactions ACSE, Paper no. 1919, Volume 100, pp. 1236-1351].

Li, M. 2008. Seepage-induced failure of widely-graded cohesionless soils. Ph.D. thesis, Dept. of Civil Engineering, The University of British Columbia, Vancouver, B.C., Canada, $303 p$

Li, M. \& Fannin, R.J. 2008. Comparison of two criteria for internal stability of granular soil. Canadian Geotechnical Journal, Vol 45 pp 1303-1309

Mejia, L. 2013. Field tests of filter materials for seismic retrofit of Matahina Dam. Proceedings ICOLD International Symposium, Seattle, pp 1989-2002.

Poulanco-Boulware, L. 2015. Modeling geomorphic features in levee reliability analyses. USSD Newsletter, July, 19-24.

Skempton, A.W. \& Brogan, J.M. 1994. Experiments on piping in sandy gravels. Geotechnique 44, No.3, 449-460.

Robbins, B.A. Sharp, M.K. \& Corcoran, M. 2015. Laboratory tests for backwards piping erosion. Proceedings $5^{\text {th }}$ International Conference on Geotechnical Safety and Risk, Rotterdam, 831-836.

Soroush, A. Shourijeh, P.T. Aghajani, H.F. \& Mohammadinia, A. 2012. A review of the sand castle test for assessing collapsibility of filter in dams. ASTM Geotechnical Testing Journal, Vol 35, No 4, 1-14

Taylor, H. Sim, W-W. \& O'Sullivan, C. 2015. Examining the potential for suffusion in micro-CT images of sands and glass beads. Proceedings, XVI Dam Monitoring International Conference, TKZ2015, Wierchomla, Poland, 165-187

Vandenboer, K. Bezuijen, A. \& Van Beek V. 2014. 3D character of backward erosion piping: small scale experiments. Proceedings, 7th International Conference on Scour and Erosion, L Cheng, S Draper \& H An (editors), Taylor \& Francis Group, London, UK, pp 81-86.

Van Beek, V.M. Bezuijen, A. Sellmeijer, J.B. \& Barends, F.B.J. 2014. Initiation of backward erosion piping in uniform sands. Geotechnique 64, No. 12, 927-941 [http://dx.doi.org/10.1680/geot.13.P.201]

Vaughan, P.R. \& Soares, H.F. 1982. Design of filters for clay cores of dams. J. Geotech. Div., ASCE. Vol. 108, GT1, 1732.

Witt, K.J. \& Vincens, E. 2012. Approaches to determine the CSD for understanding filtration phenomena in granular materials, Proc ICSE-6 ( $6^{\text {th }}$ International Conference on Scour and Erosion) Paris, August 27-31, Société Hydrotechnique de France, Paris, 105. 